\title{
A carbon network backbone polymer functionalized with polymer brushes
}

\author{
Jeffrey F Greco and Patricia A Bianconi
}

The surface-initiated graft polymerization of polymer brushes attached to an $\mathrm{sp}^{3}$ random carbon network backbone structure is demonstrated. Poly(ethyl acrylate) (PEA), poly(4-fluorostyrene) (PFS) and poly(acrylonitrile) (PAN) brushes were grafted from the network backbone polymer poly(hydridocarbyne), 1, illustrating the breadth of reactivity of the network backbone. Attachment of polymeric/oligomeric chains to the network backbone was observed through two different methods with different polymer systems. First, selective solvent extraction separated a homogeneous mixture of PEA and 1, dissolving PEA in diethyl ether, but leaving 1 behind as a brown precipitate. In contrast, 1 functionalized with PEA brushes completely dissolved, showing that it was not a homogenous mixture of the substrate and free polymeric chains, but a system of covalently bound polymer chains originating from 1 . Formation of short chains of PFS at the surface of 1 allowed the use of ${ }^{19} \mathrm{~F}$ nuclear magnetic resonance to observe the change in resonance shift and shape for the polymer side chains. Solvent extraction was used to demonstrate that tetrahydrofuran (THF) was able to separate a homogeneous mixture of PAN and 1, dissolving 1 in THF, but leaving PAN behind as a white precipitate.

Polymer Journal (2010) 42, 298-303; doi:10.1038/pj.2009.343; published online 17 February 2010

Keywords: functionalization of polymers; graft copolymers; networks; radical polymerization

\section{INTRODUCTION}

The modification of the physical and chemical properties of macromolecular and surface interfaces through adsorption or grafting of polymer brushes has become an area of intense interest and study. ${ }^{1-6}$ Polymer brush-modified substrates have been proven to be useful in increasing miscibility for polymer blends and composites, ${ }^{7-10}$ in coatings for materials ${ }^{1-13}$ and in the generation or support of organic and metallic nanoparticles. ${ }^{14-17}$ Owing to their inherent utility, a wide range of methods for the attachment of polymer brushes to a given substrate have been reported.

These methods can be placed in three general categories: physisorption, 'grafting to' and 'grafting from' a given substrate. ${ }^{18}$ Physisorption is characterized by adsorption of one polymer chain onto another, ${ }^{19-21}$ whereas both grafting methods involve a chemical reaction between the substrate surface and the polymer chain forming a covalent bond attachment (chemisorption). ${ }^{18}$ Although each method produces interesting physical characteristics at the substrate surface, the 'grafting from' method is of particular interest. The process involves initiating a polymerization reaction at the substrate surface, followed by a period of chain growth and finally, a termination step. ${ }^{18}$ As the polymer brush is being grown from the substrate surface, it is possible to achieve a higher concentration of polymer chain attachment at the substrate/polymer interface. ${ }^{3,22}$ In binding such a high density of polymer chains to a substrate's surface, the physical characteristics of the grafted polymer brush can be conferred onto the substrate.

Our laboratory previously reported the synthesis of a new class of polymers, carbon-based random network backbone polymers, designated as polycarbynes. One in particular, poly(hydridocarbyne) (1), was found to be an efficient precursor to $\mathrm{sp}^{3}$ diamond-like carbon films and to hexagonal diamond. ${ }^{23}$ These network backbone polymers are the products of the reductive condensation of bromoform using a liquid $\mathrm{Na} / \mathrm{K}$ alloy as a reducing agent (Equation 1 ).

The polymer molecules of $\mathbf{1}$ are not crosslinked to form a conventional insoluble polymer network; rather, the backbone of each polymer molecule consists of a three-dimensional random network of $\mathrm{sp}^{3}$-hybridized carbon units combined in fused rings of varying sizes, forming an overconstrained continuous random network backbone. $^{23-25}$ The polycarbynes' backbones, having three bonds between each backbone carbon atom, are therefore nonlinear, very rigid and present an almost nanoparticle-like 'surface' structure.

Each backbone carbon also bears one functional group; in the case of $\mathbf{1}$, a hydrogen, giving the empirical formula $[\mathrm{CH}]_{n}$. The functional group solubilizes the three-dimensional network backbone, allowing individual polymer molecules to dissolve and form solutions in which further reactions can be carried out. The nature of the functional group on the network backbone of polycarbynes greatly influences the solubility and reactivity characteristics of the polymer molecules. 
The surface of the network backbone of as-synthesized 1 was found to be both $\mathrm{H}$ - and Br terminated. ${ }^{23}$ It was observed that Br termination yielded negative physical properties in 1 , making it difficult to be handled for subsequent use: higher bromine content dramatically reduces the solubility of $\mathbf{1}$ in common organic solvents.

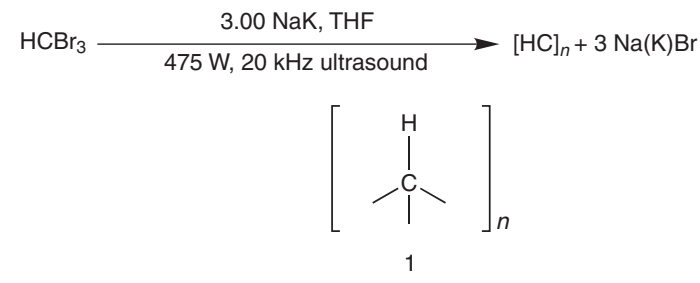

The application of $\mathrm{H}_{3} \mathrm{C}$ - 'end-caps', through a reaction with MeLi, reduced the bromide content to $0.48 \%$ and dramatically improved the physical properties ( 1 became a fine powder and was soluble in polar organic solvents such as tetrahydrofuran (THF) and methylene chloride). ${ }^{25}$ With such a dramatic change in physical properties arising from a relatively simple alteration, it was theorized that further changes in properties would be observed with the grafting of polymer brushes from the surface of the backbone of 1 . Polycarbynes being efficient as preceramic polymers, such alteration could potentially aid in the generation of new polymer composites for use in the preparation of new ceramic materials. In this study, we report the first surface modification of the polycarbyne network backbone: various polymer brushes are grafted to $\mathbf{1}$, using a free radical surface-initiated graft polymerization procedure. We also report the subsequent study of the isolated products.

\section{EXPERIMENTAL PROCEDURE}

\section{General procedures}

All reactions were carried out under an argon atmosphere, by means of standard Schlenk manipulations or inside a glovebox. Anhydrous THF was purchased from Aldrich (St Louis, MO, USA) and was dried over sodium metal and benzophenone and distilled before use. Methylene chloride was purchased from Fisher Scientific (Pittsburgh, PA, USA) and was used as received. Ethyl acrylate was purchased from Aldrich and was dried over calcium hydride and distilled before use. Bromoform, acrylonitrile, polyacrylonitrile and 2,2'-azobisisobutyronitrile (AIBN) were purchased from Aldrich and were used as received. 4-fluorostyrene was purchased from Synquest Laboratories (Alachua, FL, USA) and was used as received. 1,1,1-trifluoro-4-iodobutane (TFIB) was purchased from Alfa Aesar (Ward Hill, MA, USA) and was used as received. Methyllithium (1.6 M in diethyl ether) was purchased from Aldrich and was at first used as received, and was later titrated to determine the correct concentration. Liquid 1:1 NaK alloy was prepared in a glovebox by adding solid potassium to an equimolar amount of molten sodium. Caution! NaK alloy is pyrophoric and can be explosively reactive with water and halocarbons. Handle with all necessary precautions and in inert atmospheres only.

Elemental analyses were performed by Galbraith Laboratories Inc. (Knoxville, TN, USA). All solution ${ }^{1} \mathrm{H}$ and ${ }^{13} \mathrm{C}\left\{{ }^{1} \mathrm{H}\right\}$ nuclear magnetic resonance (NMR) spectra were recorded on Bruker Avance 400 and Bruker DPX300 spectrometers (Bruker BioSpin, Billerica, MA, USA). Solid state ${ }^{13} \mathrm{C}\left\{{ }^{1} \mathrm{H}\right\}$ and ${ }^{19} \mathrm{~F}$ NMR spectra were recorded on a Bruker DPX300 spectrometer. FTIR transmission spectra were obtained using a Midac (Costa Mesa, CA, USA) instrument. The molecular weights of polymers were determined by comparison with a narrow molecular weight polystyrene standard by gel permeation chromatography using a flow rate of $1 \mathrm{ml} \mathrm{min}^{-1}$ (THF with $0.01 \mathrm{M}$ toluene as the solvent at $50^{\circ} \mathrm{C}$ ), a crosslinked polystyrene column (PL gel) and an RI detector (wellchrome KL-2301). Electronic spectra were measured using a Shimadzu UV2401PC (Shimadzu, Columbia, MD, USA) with a photomultiplier R-928 detector and $50 \mathrm{~W}$ halogen and deuterium lamps.

\section{Preparation of Poly(hydridocarbyne) (1)}

An oven-dried 600-ml beaker was placed in an argon atmosphere drybox equipped with a high-intensity $(475 \mathrm{~W}, 20 \mathrm{kHz}, 1 / 2$ in. tip) Heat Systems (Farmingdale, NY, USA) ultrasonic immersion horn and was charged with THF $(200 \mathrm{ml})$ and sodium potassium alloy $(2.33 \mathrm{~g}, 37.5 \mathrm{mmol})$. The ultrasonic horn was placed at a depth of 1 inch below the surface of the liquid, and the solvents were irradiated at $55 \%$ power output for $5 \mathrm{~min}$, producing a sky-blue emulsion. Bromoform $(6.32 \mathrm{~g}, 25 \mathrm{mmol})$ was diluted with $40 \mathrm{ml}$ of THF and added dropwise to the $\mathrm{NaK}$ emulsion over $\sim 10 \mathrm{~min}$ while being sonicated as before. During the addition, the reaction mixture heated to reflux; care was taken to control the vigor of the reaction by controlling the rate of addition of the remaining bromoform. The emulsion became dark brown/purple and finally became black on complete addition. After the addition was completed, sonication was continued for $20 \mathrm{~min}$. Methyllithium $(6.0 \mathrm{ml}, 1.6 \mathrm{M}$ in diethyl ether) was added by means of a syringe, followed by another $20 \mathrm{~min}$ sonication period. The black mixture was allowed to cool and was then transferred to a shielded fume hood under ambient atmosphere. Water was carefully added with vigorous stirring to quench any unreacted $\mathrm{NaK}$ and methyllithium. The solvents were evaporated off, leaving a dark brown waxy solid, combined with white bands of salts. Dichloromethane (about $100 \mathrm{ml}$ ) was added, and the mixture was stirred for $5 \mathrm{~min}$ and filtered through a plug of Celite. The resulting brown solution was reduced in volume by half; hexanes $(\sim 25 \mathrm{ml})$ were gradually added until a fine tan precipitate of poly(hydridocarbyne), $\mathbf{1}$, formed, which was gravity filtered and air dried. The resulting crude product was washed with water to remove any remaining salts, gravity filtered and again air dried. The polymer was typically obtained as a fine tan solid in yields of $0.15-0.28 \mathrm{~g}(46-85 \%)$. Additional polymer could be obtained by evaporating the filtrate solution to dryness, redissolving the solids in minimum dichloromethane, and precipitating with hexanes as before. ${ }^{1} \mathrm{H}$ NMR $(400 \mathrm{mHz}$, $\mathrm{CDCl}_{3}$ ): $\delta$ 0.5-2.5 (weak broad, $\left.\mathrm{CH}\right), 1.30,1.65\left(\mathrm{C}-\mathrm{CH}_{3}\right)$ p.p.m. Anal. calculated for $(\mathrm{CH})$ : C, 92.31; H, 7.69. Found: C, 65.31; H, 7.79; Br, 0.48; $\mathrm{Na},<0.2 ; \mathrm{K},<0.4$. (The chemical analyses of all polymers containing the polycarbyne backbone are significantly low in carbon. ${ }^{25} \mathrm{~A}$ large portion of the carbyne backbone is converted to hard, oxidation-resistant carbon during combustion analysis, resulting in the low carbon values obtained. Similarly low values are seen in the combustion analyses of many molecular and polymer precursors to refractory ceramics.)

\section{Preparation of PFS}

An oven-dried 100-ml round-bottomed Schlenk flask was charged with a solution of 4-fluorostyrene $(1.25 \mathrm{~g}, 10.2 \mathrm{mmol})$ and azoisobutyrylnitrile (AIBN) $(0.0850 \mathrm{~g}, 0.518 \mathrm{mmol})$ in anhydrous THF $(15 \mathrm{ml})$. The reaction solution was heated to and sustained at $70^{\circ} \mathrm{C}$ for $12 \mathrm{~h}$. On cooling, THF was evaporated, leaving a brittle white solid. Precipitation from methylene chloride with hexanes yielded the product as a white powder $(0.953 \mathrm{~g}) .{ }^{1} \mathrm{H}$ NMR $\left(300 \mathrm{mHz}, \mathrm{CDCl}_{3}\right): \delta 6.80\left(\mathrm{Br}, 2 \mathrm{H},-\mathrm{CH}_{2}-\mathrm{CH}\left(\mathrm{C}_{6} \mathrm{H}_{4} \mathrm{~F}\right)-\right), 6.47\left(\mathrm{Br}, 2 \mathrm{H},-\mathrm{CH}_{2}-\right.$ $\left.\mathrm{CH}\left(\mathrm{C}_{6} \mathrm{H}_{4} \mathrm{~F}\right)-\right), 1.58\left(\mathrm{Br}, 1 \mathrm{H},-\mathrm{CH}_{2}-\mathrm{CH}\left(\mathrm{C}_{6} \mathrm{H}_{4} \mathrm{~F}\right)-\right), 1.39\left(\mathrm{Br}, 2 \mathrm{H},-\mathrm{CH}_{2}-\right.$ $\left.\mathrm{CH}\left(\mathrm{C}_{6} \mathrm{H}_{4} \mathrm{~F}\right)-\right)$ p.p.m. ${ }^{19} \mathrm{~F}$ NMR $\left(300 \mathrm{mHz}, \mathrm{CDCl}_{3}\right): \delta-116.0(\mathrm{Br}),-116.7$ to -117.1 (Br) p.p.m.

\section{Preparation of PEA}

This procedure was carried out as with PFS, using ethyl acrylate $(8.00 \mathrm{ml}$, $73.6 \mathrm{mmol})$ and AIBN $(0.616 \mathrm{~g}, 3.76 \mathrm{mmol})$ in THF $(50 \mathrm{ml})$. The product was obtained as a clear, light brown, highly viscous liquid. ${ }^{1} \mathrm{H} \mathrm{NMR}(400 \mathrm{mHz}$, $\left.\mathrm{CDCl}_{3}\right): \delta 4.12\left(\mathrm{Br}, 2 \mathrm{H},-\mathrm{CH}_{2}-\mathrm{CH}\left(\mathrm{C}(\mathrm{O}) \mathrm{O}-\mathrm{CH}_{2}-\mathrm{CH}_{3}\right)-\right), 3.76\left(\mathrm{Br}, 2 \mathrm{H},-\mathrm{CH}_{2}-\right.$ $\left.\mathrm{CH}\left(\mathrm{C}(\mathrm{O}) \mathrm{O}-\mathrm{CH}_{2}-\mathrm{CH}_{3}\right)-\right), 2.31\left(\mathrm{Br}, 1 \mathrm{H},-\mathrm{CH}_{2}-\mathrm{CH}\left(\mathrm{C}(\mathrm{O}) \mathrm{O}-\mathrm{CH}_{2}-\mathrm{CH}_{3}\right)-\right), 1.25$ $\left(\mathrm{Br}, 3 \mathrm{H},-\mathrm{CH}_{2}-\mathrm{CH}\left(\mathrm{C}(\mathrm{O}) \mathrm{O}-\mathrm{CH}_{2}-\mathrm{CH}_{3}\right)-\right)$ p.p.m. ${ }^{13} \mathrm{C} \mathrm{NMR}\left(400 \mathrm{mHz}, \mathrm{CDCl}_{3}\right)$ : $\delta 173.90\left(-\mathrm{CH}_{2}-\mathrm{CH}\left(\mathrm{C}(\mathrm{O}) \mathrm{O}-\mathrm{CH}_{2}-\mathrm{CH}_{3}\right)-\right), 61.32\left(-\mathrm{CH}_{2}-\mathrm{CH}\left(\mathrm{C}(\mathrm{O}) \mathrm{O}-\mathrm{CH}_{2}-\right.\right.$ $\left.\left.\mathrm{CH}_{3}\right)_{-}\right), 40.98\left(-\mathrm{CH}_{2}-\mathrm{CH}\left(\mathrm{C}(\mathrm{O}) \mathrm{O}-\mathrm{CH}_{2}-\mathrm{CH}_{3}\right)-\right), 35.18\left(-\mathrm{CH}_{2}-\mathrm{CH}(\mathrm{C}(\mathrm{O}) \mathrm{O}-\right.$ $\left.\left.\mathrm{CH}_{2}-\mathrm{CH}_{3}\right)-\right), 13.98\left(-\mathrm{CH}_{2} \mathrm{CH}\left(\mathrm{C}(\mathrm{O}) \mathrm{O}-\mathrm{CH}_{2}-\mathrm{CH}_{3}\right)-\right)$ p.p.m. infrared (IR): $2969(\mathrm{~m}), 2935(\mathrm{~m}), 2850(\mathrm{w}), 1724(\mathrm{~s})\left(v_{\mathrm{CO}}\right), 1451(\mathrm{~m}), 1426(\mathrm{~s}), 1184(\mathrm{~s})$, $1166(\mathrm{~s}), 1094(\mathrm{~m}), 1063(\mathrm{~m}), 1017(\mathrm{~m}) \mathrm{cm}^{-1}$.

\section{Preparation of PFS-functionalized 1 (1/PFS)}

All functionalization reactions were carried out as follows. An oven dried $100-\mathrm{ml}$ round-bottomed Schlenk flask was charged with a solution of 
$1(0.165 \mathrm{~g}, 12.7 \mathrm{mmol})$ and AIBN $(0.102 \mathrm{~g}, 0.621 \mathrm{mmol})$ in THF $(25 \mathrm{ml})$ and equipped with a reflux condenser. The solution was stirred at $70^{\circ} \mathrm{C}$ for $1 \mathrm{~h}$, after which a solution of 4 -fluorostyrene $(0.157 \mathrm{~g}, 1.29 \mathrm{mmol})$ in THF $(10 \mathrm{ml})$ was added by means of a syringe and stirred at $70^{\circ} \mathrm{C}$ for $12 \mathrm{~h}$. The THF was evaporated, leaving a tacky brown solid that was taken up in methylene chloride $(15 \mathrm{ml})$. Gradual addition of hexanes precipitated the product as a pale orange/ brown powder $(0.253 \mathrm{~g})$. The product was reprecipitated from methylene chloride and hexanes as before. ${ }^{1} \mathrm{H}$ NMR $\left(400 \mathrm{mHz}, \mathrm{CDCl}_{3}\right): \delta 6.72$ (very weak $\left.\mathrm{Br},-\mathrm{CH}_{2}-\mathrm{CH}\left(\mathrm{C}_{6} \mathrm{H}_{4} \mathrm{~F}\right)-\right)$ ), 6.40 (very weak $\mathrm{Br},-\mathrm{CH}_{2}-\mathrm{CH}\left(\mathrm{C}_{6} \mathrm{H}_{4} \mathrm{~F}\right)-$ ), 2.5-0.5 (weak $\mathrm{Br}, \mathrm{CH}(\mathrm{PHC})$ ) p.p.m. ${ }^{19} \mathrm{~F} \mathrm{NMR}\left(300 \mathrm{mHz}, \mathrm{CDCl}_{3}\right): \delta-115.6$ to -117.2 (Br) p.p.m. IR: 3115 (s), 3040 (s), 2929 (s), 2583 (s), 1886 (s), 1619 (s), 1540 (s), 1447 (s), 1415 (s), 1367 (s), 1296 (s), 1229 (s), 1096 (s), 1012 (s), 830 (s). Gel permeation chromatography (GPC) analysis: $\bar{M}_{\mathrm{n}}=6500, \bar{M}_{\mathrm{w}}=11700, P=1.80$.

\section{Preparation of PAN-functionalized 1 (1/PAN)}

The synthesis was carried out as for $1 / P F S$, using $1(0.519 \mathrm{~g}, 39.9 \mathrm{mmol})$, AIBN $(0.334 \mathrm{~g}, 2.04 \mathrm{mmol})$ and acrylonitrile $(5.26 \mathrm{ml}, 79.9 \mathrm{mmol})$. After stirring the reaction mixture at $70^{\circ} \mathrm{C}$ for $3 \mathrm{~h}$, a tan solid precipitated out of the solution. The reaction mixture was filtered and the solid product was washed with hexanes $(50 \mathrm{ml})$, water $(50 \mathrm{ml})$ again with hexanes $(50 \mathrm{ml})$ and dried in vacuo yielding the product as a tan solid $(2.34 \mathrm{~g}) .{ }^{1} \mathrm{H}$ NMR $\left(400 \mathrm{mHz}, \mathrm{d}^{6}\right.$-dimethylsulfoxide): $\delta 3.15\left(\mathrm{Br},-\mathrm{CH}_{2}-\mathrm{CH}(\mathrm{CN})-\right), 2.09\left(\mathrm{Br},-\mathrm{CH}_{2}-\mathrm{CH}(\mathrm{CN})-\right)$ p.p.m. ${ }^{13} \mathrm{C}$ CPMAS NMR: $\delta 119\left(\mathrm{Br},-\mathrm{CH}_{2}-\mathrm{CH}(\mathrm{CN})-\right), 29\left(\mathrm{Br},-\mathrm{CH}_{2}-\mathrm{CH}(\mathrm{CN})-\right)$ p.p.m. IR: $2938(\mathrm{w}), 2874(\mathrm{w}), 2241(\mathrm{~m})\left(v_{\mathrm{CN}}\right), 1455(\mathrm{~m}), 1351(\mathrm{~s}), 1155(\mathrm{~s}), 985(\mathrm{~s})$, 832 (s) $\mathrm{cm}^{-1}$. Anal. found: C 66.25, H 6.11, N 20.69 .

\section{Preparation of PEA-functionalized 1 (1/PEA)}

Synthesis and isolation were carried out as with $1 / P F S$, using $1(0.102 \mathrm{~g}$, $7.85 \mathrm{mmol})$, AIBN $(0.071 \mathrm{~g}, 0.433 \mathrm{mmol})$ and ethyl acrylate $(1.7 \mathrm{ml}$, $15.64 \mathrm{mmol}$ ). 1/PEA was isolated as a sticky brown gel-like substance, and was purified by precipitation from a solution of methylene chloride $(5 \mathrm{ml})$ and hexanes $(150 \mathrm{ml})$. The overall yield was $0.575 \mathrm{~g} .{ }^{1} \mathrm{H} \mathrm{NMR}\left(400 \mathrm{mHz}, \mathrm{CDCl}_{3}\right)$ : $\delta 4.14\left(\mathrm{Br}, 2 \mathrm{H},-\mathrm{CH}_{2}-\mathrm{CH}\left(\mathrm{C}(\mathrm{O}) \mathrm{O}-\mathrm{CH}_{2}-\mathrm{CH}_{3}\right)-\right), 3.80\left(\mathrm{Br}, 2 \mathrm{H},-\mathrm{CH}_{2}-\right.$ $\left.\mathrm{CH}\left(\mathrm{C}(\mathrm{O}) \mathrm{O}-\mathrm{CH}_{2}-\mathrm{CH}_{3}\right)-\right), 2.32\left(\mathrm{Br}, 1 \mathrm{H},-\mathrm{CH}_{2}-\mathrm{CH}\left(\mathrm{C}(\mathrm{O}) \mathrm{O}-\mathrm{CH}_{2}-\mathrm{CH}_{3}\right)-\right)$, $1.28\left(\mathrm{Br}, 3 \mathrm{H},-\mathrm{CH}_{2}-\mathrm{CH}\left(\mathrm{C}(\mathrm{O}) \mathrm{O}-\mathrm{CH}_{2}-\mathrm{CH}_{3}\right)-\right)$ p.p.m. ${ }^{13} \mathrm{C} \mathrm{NMR}(400 \mathrm{mHz}$, $\left.\mathrm{CDCl}_{3}\right): \delta 174.5\left(-\mathrm{CH}_{2}-\mathrm{CH}\left(\mathrm{C}(\mathrm{O}) \mathrm{O}-\mathrm{CH}_{2}-\mathrm{CH}_{3}\right)-\right), 60.51\left(-\mathrm{CH}_{2}-\mathrm{CH}(\mathrm{C}(\mathrm{O}) \mathrm{O}-\right.$ $\left.\left.\mathrm{CH}_{2}-\mathrm{CH}_{3}\right)-\right), \quad 41.47 \quad\left(-\mathrm{CH}_{2}-\mathrm{CH}\left(\mathrm{C}(\mathrm{O}) \mathrm{O}-\mathrm{CH}_{2}-\mathrm{CH}_{3}\right)-\right), \quad 35.22 \quad\left(-\mathrm{CH}_{2}-\right.$ $\left.\mathrm{CH}\left(\mathrm{C}(\mathrm{O}) \mathrm{O}-\mathrm{CH}_{2}-\mathrm{CH}_{3}\right)-\right), 14.17\left(-\mathrm{CH}_{2}-\mathrm{CH}\left(\mathrm{C}(\mathrm{O}) \mathrm{O}-\mathrm{CH}_{2}-\mathrm{CH}_{3}\right)-\right)$ p.p.m. IR: $2975(\mathrm{~m}), 2941(\mathrm{~m}), 2872(\mathrm{w}), 1729(\mathrm{~s})\left(v_{\mathrm{CO}}\right), 1446(\mathrm{~m}), 1420(\mathrm{~s}), 1179(\mathrm{~s})$, $1162(\mathrm{~s}), 1093(\mathrm{~m}), 1059(\mathrm{~m}), 1020(\mathrm{~m}) \mathrm{cm}^{-1}$. GPC analysis: $\bar{M}_{\mathrm{n}}=7000$, $\bar{M}_{\mathrm{w}}=13720, P=1.96$.

\section{RESULTS AND DISCUSSION}

\section{Reactivity of 1 with AIBN}

To maximize the concentration of polymer brushes bound to $\mathbf{1}$, backbone-initiated graft polymerization of alkene monomers was chosen as the method of application. Free radical initiators, such as AIBN, could be used to abstract hydrogen or bromine radicals from the backbone surface, ${ }^{26}$ leaving initiation sites suitable for free radical polymerization and growth of oligomeric/polymeric side chains from 1. ${ }^{22,27-29}$ As this kind of reactivity had not been explored with 1 , proving that radical initiators could actually effect a reaction at the surface of the polymer was considered to be the starting point.

AIBN was chosen as the free radical initiator because of its proven reactivity with halogenated dodecahedranes, molecules that have a structure analogous to the network backbone of 1 . A THF solution of $5 \mathrm{~mol} \% \mathrm{AIBN}$ and 1 was heated to $70^{\circ} \mathrm{C}$ and stirred for $1 \mathrm{~h}$, after which $35 \mathrm{~mol} \%$ of TFIB was added to the reaction mixture and stirred at $70{ }^{\circ} \mathrm{C}$ for $12 \mathrm{~h}$. Any surface radicals on the network polymer backbone would homolytically cleave the carbon-iodine bond, forming $\mathrm{I}_{2}^{8,26,30}$ and thus allowing for the radical addition of the 1,1 , 1-trifluorobutane fragment to 1 .

${ }^{19} \mathrm{~F}$ NMR was used to monitor the change in the fluorine signal in the 1,1,1-trifluorobutane fragment on attachment to the rigid a

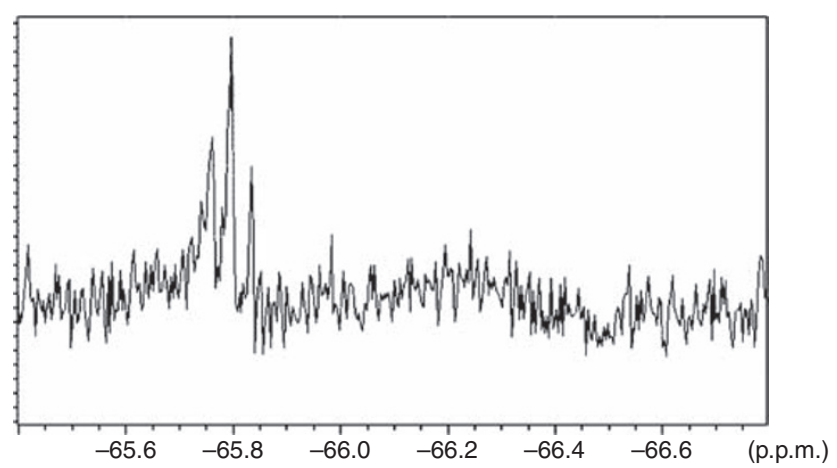

b

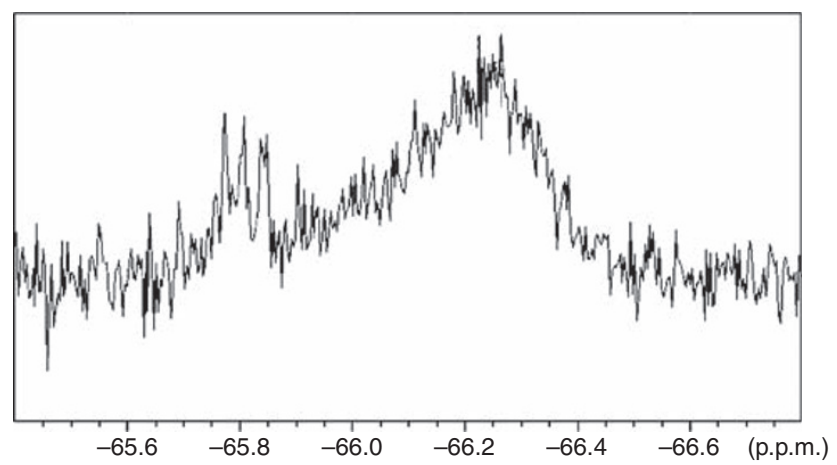

Figure $1{ }^{19} \mathrm{~F}$ NMR of (a) pure TFIB and (b) isolated product of AIBNinitiated TFIB radical addition to 1 .

backbone, or any in products of side reactions that may have taken place between molecules of TFIB. It has been observed that functional groups that covalently bind to the rigid network backbone of $\mathbf{1}$ and of other polycarbynes experience significant signal broadening due to short $\mathrm{T}_{2}$ relaxation times. ${ }^{23,31,32}$ The ${ }^{19} \mathrm{~F}$ NMR spectrum of $\mathbf{1}$ heated with TFIB (no added AIBN) showed that no reaction had occurred: only pure TFIB was observed.

A comparison between the ${ }^{19} \mathrm{~F}$ NMR spectra of pure TFIB and that of the brown powder isolated from the 1 /TFIB/AIBN reaction mixture (which ${ }^{1} \mathrm{H}$ NMR confirmed was primarily $\mathbf{1}$ : any signals corresponding to 1,1,1-trifluorobutane fragments were unobservable because of the broad ${ }^{1} \mathrm{H}$ signal of $\mathbf{1}$ ) shows a marked change in the fluorine signal (Figure 1). On inspection of spectra $\mathbf{A}$ and $\mathbf{B}$, it is apparent that the chemical environment of the fluorinated species changed dramatically on reaction with $\mathbf{1}$. In spectrum A, pure TFIB appears as a sharp triplet centered at -65.80 p.p.m., but on reaction with AIBN-activated 1, spectrum B, two signals (the triplet associated with pure TFIB and a broad signal extending from -65.85 and -66.50 p.p.m.) were observed. (The unreacted TFIB can be removed by washing the product with diethyl ether, but was used as a visual reference in the ${ }^{19} \mathrm{~F}$ NMR spectrum.) The new signal demonstrates the line broadening expected when the 1,1,1-trifluorobutane fragment is bound to the rigid network backbone of 1 . The absence of other signals in the ${ }^{19} \mathrm{~F}$ NMR spectrum indicated that no significant side reactions involving TFIB took place. Therefore, it was concluded that there were little to no 1,1,1-trifluorobutane radical fragments formed in solution, indicating that the primary reactive sites in the reaction solution were at the surface of $\mathbf{1}$.

These results demonstrate that AIBN is indeed effective in activating the surface of $\mathbf{1}$ toward free radical substitution reactions, and is potentially useful as a surface-initiated graft polymerization activator. 

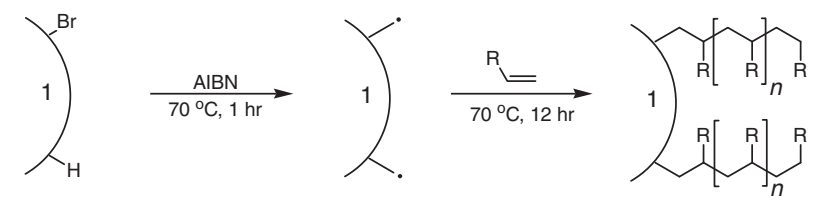

$(1 / \mathrm{PEA}): \mathrm{R}=-\mathrm{C}(\mathrm{O}) \mathrm{OC}_{2} \mathrm{H}_{5}$

(1/PAC) : $R=-C N$

(1/PFS): $\mathrm{R}=-\mathrm{C}_{6} \mathrm{H}_{4} \mathrm{~F}$

Scheme 1 Surface-initiated graft polymerization of ethyl acrylate, acrylonitrile and 4-fluorostyrene onto 1 .

\section{Surface-initiated graft polymerization studies}

Polymer-brush functionalization of $\mathbf{1}$ was carried out by first heating a THF solution of 1 and $5 \mathrm{~mol} \%$ of AIBN, followed by the addition of a THF solution of one of the three selected monomers: ethyl acrylate, acrylonitrile or 4-fluorostyrene (Scheme 1). Crude 1/PEA and 1/PFS were isolated by removal of THF under vacuum and were purified by precipitation from methylene chloride with hexanes. These products consisted of a clear, brown, highly viscous liquid, and a brown solid, respectively. 1/PAN precipitated out of the reaction solution as a light tan solid, was isolated by filtration and washed with THF. PEA and PFS homopolymers were also synthesized, using the same conditions as above. They were isolated as a clear, colorless, highly viscous liquid, and as a white solid, respectively. PAN homopolymer was purchased from Aldrich and was obtained as a white powder.

\section{Polymer brush attachment: 1/PEA}

To confirm that the PEA obtained from the polymerization reaction was indeed covalently bound to 1 , several methods were used. The initial step was to confirm the presence of both species. ${ }^{1} \mathrm{H}$ NMR, ${ }^{13} \mathrm{C}$ NMR and IR spectroscopy displayed only signals comparable with PEA homopolymer (see Experimental procedure section). This was expected, because of the large molar excess of PEA present in the isolated product and the very weak, very broad, ${ }^{1} \mathrm{H}$ and ${ }^{13} \mathrm{C}$ NMR signals generated by 1. ${ }^{23}$ Electronic spectroscopy, however, showed the characteristic signal of 1 , an intense broad absorption extending from $\sim 200$ to $600 \mathrm{~nm}^{23}$

Inspection of the ultraviolet (UV) spectrum of PEA $\left(\lambda_{\max }=222 \mathrm{~nm}\right)$ revealed that its signal would be completely buried beneath the intense absorption of 1 . Whereas NMR and UV spectra confirmed the presence of both 1 and PEA, neither was able to demonstrate that PEA was covalently bound to 1 (1/PEA), or if the sample might be composed of a physical mixture of PEA and 1 homopolymers. (Note that the common polymer characterization methods of DSC and TGA are not useful in the case of polymer-brush functionalized polycarbynes, because of the network backbones' rapid decomposition to carbon ceramics.) A physical mixture would theoretically be able to be separated and characterized by GPC (a bimodal trace should be visible in the spectrum of a physical mixture). On GPC analysis of the separated (by THF washing) mixture, only a unimodal trace was observed $\left(\bar{M}_{\mathrm{n}}=7000, \bar{M}_{\mathrm{w}}=13720, P=1.96\right)$, consistent with there being only one polymeric species present in the isolated product. (Because of the very different shapes and hydrodynamic properties of the polycarbynes' network backbones and the linear backbones of the polystyrene standards used in conventional GPC analysis, the molecular weights of the polycarbynes given by such analyses are always found to be very low. Such low molecular weight values are experimental artifacts, and are useful only for comparison purposes. The absolute molecular weight of $\mathbf{1}$ was determined to range between 200000 and 2.6 million, ${ }^{23}$ although the molecular weights of this
Table 1 Solubility in diethyl ether of pure PEA, 1, PEA:1 homopolymer mixture and 1/PEA

\begin{tabular}{ll}
\hline Sample & Solubility in diethyl ether \\
\hline PEA & Soluble \\
1 & Insoluble \\
PEA:1 homopolymer mixture & PEA homopolymer: soluble \\
& 1 homopolymer: insoluble \\
1/PEA & Soluble $^{\mathrm{c}}$
\end{tabular}

Abbreviations: 1, poly(hydridocarbyne); PEA, poly(ethyl acrylate).

${ }^{\mathrm{a}}$ Clear colorless solution.

bBrown solid.

clear brown solution.

polymer were given as below 10000 by conventional GPC analyses using linear polystyrene standards.)

To confirm this assessment, selective solvent extraction experiments (results summarized in Table 1) were conducted on both a physical mixture of 1 and PEA homopolymers, and also on the 1/PEA reaction product. First, the solubility of 1 and of PEA in diethyl ether was tested. It was observed that, whereas homo-PEA completely dissolved in ether, 1 was insoluble. On confirmation of their difference in solubility in diethyl ether, equal amounts of homopolymers 1 and PEA were dissolved in THF and mixed, forming a clear brown solution. The THF was removed under reduced pressure, yielding a clear brown highly viscous solution resembling the product from the surfaceinitiated graft polymerization reaction (1/PEA). This homogeneous mixture was then extracted with diethyl ether. Filtration produced a clear colorless solution, which, on exposure to reduced pressure, yielded a clear colorless highly viscous liquid, which ${ }^{1} \mathrm{H}$ NMR confirmed was PEA, and an ether-insoluble brown solid, 1 (confirmed to be 1 by ${ }^{1} \mathrm{H}$ NMR and UV spectroscopies).

Selective solvent extraction proved to be an effective method for the separation of a homogeneous mixture of $\mathbf{1}$ and PEA, and could now be used to test whether the product obtained from the surfaceinitiated graft polymerization was indeed 1/PEA, or was simply a physical mixture of the homopolymers. When diethyl ether was added to a sample of the $1 / \mathrm{PEA}$ reaction product, a clear brown solution was formed. Unlike that seen in the control experiment, no brown precipitate of 1 was observed. If the product was indeed a physical mixture, then, according to previous results with 1 and PEA homopolymer mixtures, 1 should have precipitated out of solution. This experiment demonstrated that the product obtained from the surfaceinitiated graft polymerization of $\mathbf{1}$ with ethyl acrylate indeed produced polymer brushes covalently bound to the surface of 1 . These imparted the solubility characteristics of PEA to the network backbone of 1 .

\section{Polymer brush attachment: 1/PFS}

To produce a spectroscopic demonstration of the covalent attachment of polymer brushes to $1,10 \mathrm{~mol} \%$ of 4 -fluorostyrene was reacted with AIBN-activated 1. Such a small amount of monomer was expected to produce short oligomeric chains that were surface grafted to 1 , and thus have a similar effect on the ${ }^{19} \mathrm{~F}$ NMR spectrum that was observed for the reaction of 1 with TFIB. Analysis of the product, 1/PFS, with ${ }^{1} \mathrm{H}$ NMR and UV-visible spectroscopy confirmed the presence of $\mathbf{1}$. Comparison with the UV spectrum of $1 / \mathrm{PFS}$ and a sample of pure PFS homopolymer $\left(\lambda_{\max }=250 \mathrm{~nm}\right.$, prepared by AIBN free radical polymerization) again demonstrated that the signal contribution from PFS was buried under the sizeable absorption of 1 .

The GPC spectrum of purified 1/PFS displayed a unimodal trace $\left(\bar{M}_{\mathrm{n}}=6500, \bar{M}_{\mathrm{w}}=11,700, P=1.80\right)$, indicating the presence of one 


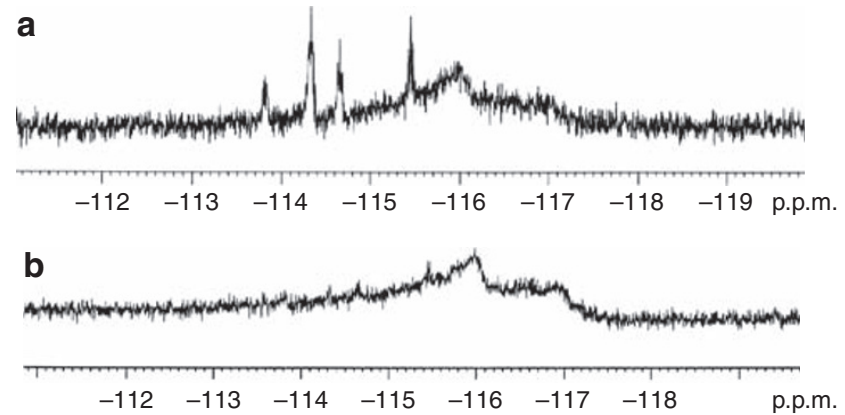

Figure $2{ }^{19} \mathrm{~F}$ spectra of 1/PFS before (a) and after (b) extraction with diethyl ether.

polymeric species. The ${ }^{1} \mathrm{H}$ NMR spectrum displayed very weak resonances at 6.72 and 6.40 p.p.m., which correspond to PFS aromatic signals. These spectroscopic results are consistent with the small amount of the monomer used, and thus the small ratio of PFS oligomers to molecules of 1 . Examination of 1/PFS with ${ }^{19} \mathrm{~F}$ NMR showed a mixture of products (Figure 2a). The four sharp signals at $-113.8,-114.3,-114.7$ and -115.5 p.p.m. indicate the presence of oligomeric chains of PFS formed in solution and not covalently bound to 1 . However, a very broad ${ }^{19} \mathrm{~F}$ resonance appearing between -115.6 and -117.2 p.p.m. indicated oligomeric PFS attached to the backbone of 1 in the 1/PFS reaction product.

To remove free PFS oligomers, the sample was extracted with diethyl ether, yielding a clear colorless solution and an ether-insoluble brown solid. Spectrum B of Figure 2, the ${ }^{19} \mathrm{~F}$ spectrum of the brown solid, indicates that $\mathbf{1}$ is functionalized with surface-grafted oligomers of PFS: the resonance again displays the broad signal customary of a functional group bound to the rigid network backbone of $\mathbf{1}$. Characterization of the ether extract showed the free PFS oligomeric species observed in spectrum 2A. These data in combination with the solvent separation experiments described above demonstrate that the oligomeric/polymeric chains produced in the surface-initiated graft polymerization reactions with ethyl acrylate and 4-fluorostyrene are covalently attached to the backbone of $\mathbf{1}$.

\section{Polymer attachment: 1/PAN}

Interest in the PAN system stemmed from the possibility of generating a polymer composite of PAN and $\mathbf{1}$. This composite could potentially be used to generate carbon fibers with gradient regions of diamondlike carbon. These regions could provide greater tensile strength and improve the overall machining properties of carbon fibers. ${ }^{33}$ Surface initiation and polymerization of acrylonitrile was accomplished using the same free radical activation of the backbone of $\mathbf{1}$ that was described for the case of ethyl acrylate.

The reaction product's (1/PAN) physical properties differed dramatically from those of 1 /PEA. Whereas 1 /PEA was readily soluble in THF and diethyl ether, 1/PAN was insoluble in both. Only highly polar organic solvents, such as dimethylsulfoxide, were capable of dissolving 1/PAN. These solubility properties were identical to those of PAN homopolymer, as shown in control studies. ${ }^{1} \mathrm{H},{ }^{13} \mathrm{C}$ CPMAS NMR and IR spectroscopy all confirmed the presence of PAN in the 1/PAN reaction product. UV-visible spectroscopy displayed the characteristic absorption for 1. Comparison of the UV spectrum with that of homopolymeric PAN $\left(\lambda_{\max }=286 \mathrm{~nm}\right)$ showed that any electronic absorption arising from the homopolymer would be completely buried in the signal of 1 .
The fact that $\mathbf{1}$ was no longer soluble in THF suggests that graft polymer or oligomer chains of PAN were covalently bound to the surface of 1 and drastically altered its solubility properties. If 1/PAN had been a mixture of homopolymers, THF would have been able to extract pure $\mathbf{1}$ and separate it from the $\mathbf{1}$ and PAN mixture. Owing to the low solubility of PAN in most organic solvents, a slightly different selective solubility study than those mentioned above was conducted to prove covalent attachment of PAN to 1 . In this test, the high solubility of 1 in THF was used to separate a physical mixture of PAN and 1. The mixture was generated by dissolving equal parts of both species (PAN as a white powder, 1 as a brown powder) in dimethylsulfoxide, giving a clear brown solution. Removal of the solvent yielded a tan solid mixture of PAN and 1. Extraction of this mixture with THF produced a clear brown solution, leaving behind an insoluble white solid. A brown powder was recovered from the THF solution, which NMR and UV analysis confirmed to be pure 1 . The white solid was confirmed to be pure PAN, proving that a homogeneous mixture of PAN and $\mathbf{1}$ could be separated by simple extraction methods.

When THF was added to a sample of 1/PAN (a tan powder), the resulting solution was clear and colorless; no change was observed in the tan powder. The lack of solubility of $1 / \mathrm{PAN}$, compared with the high solubility of $\mathbf{1}$ homopolymer, demonstrates that PAN chains were again grafted to the $\mathbf{1}$ network backbone and had imparted the solubility characteristics of PAN (insoluble in THF) to 1/PAN. UV-visible analysis of the THF extraction solvent showed no signal for 1 . These results again indicate covalent attachment of the polymer chains to 1 . Owing to the solubility issues of 1/PAN, GPC measurements could not be conducted with the sample.

\section{CONCLUSION}

We have shown that surface-initiated graft polymerization of covalently bound polymer brushes attached to an $\mathrm{sp}^{3}$ random carbon network backbone structure is possible for three alkene monomers. The polycarbyne network backbone is easily activated by the free radical initiator AIBN, and becomes capable of initiating free radical reactions independently. As many monomers can be polymerized by free radical polymerization, this method provides a versatile means for functionalization of polycarbyne network backbone polymers, thus altering their physical properties. The network backbone polymer brush-modified substrate could prove to be useful in increasing the polycarbyne's miscibility for polymer blends and composites and for coatings for materials, as well as the generation or support of organic and metallic nanoparticles. Further research into the applicability of this method toward the formation of polymer composites of $\mathbf{1}$ and PAN for the subsequent generation of diamond-like carbon-reinforced carbon fibers will be conducted.

\section{ACKNOWLEDGEMENTS}

We acknowledge Hexcel Corporation and DARPA (Contract HR0011-06-C-0011) for support of this research.

1 Ishizu, K. \& Fukukawa, T. Architecture and surfactant behaviors of amphiliphilic prototype and AB-Block type copolymer brushes. in Focus on Polymeric Materials Research (ed. Caruta, B. M.) 29-48 (Nova Science Publishers, Hauppauge, NY, 2006).

$2 \mathrm{Ni}, \mathrm{G}$., Yang, W., He, X., Bo, L. \& Lu, W. Advances in surface initiated polymerization. Prog. Chem. 17, 1074-1080 (2005).

3 Tsujii, Y., Ohno, K., Yamamoto, S., Goto, A. \& Fukuda, T. Structure and properties of high-density polymer brushes prepared by surface-initiated living radical polymerization, in Advances in Polymer Science: Surface-Initiated Polymerization I (ed. Jordan, R.), Vol. 197, Ch. 1, 1-45 (Springer, Berlin, 2006). 
4 Arslan, H., Yesilyurt, N. \& Hazer, B. The synthesis of poly(3-hydroxybutyrate)-g poly(methylmethacrylate) brush type graft copolymers by atom transfer radical polymerization method,. J. of Appl. Polym. Sci. 106, 1742-1750 (2007).

5 Liu, P. Modification of polymeric materials via surface-initiated controlled/'living' radical polymerization. E-Polymers 062 (2007).

6 Neugebauer, D. Graft copolymers with poly(ethylene oxide) segments. Polym. Intl. 56, 1469-1498 (2007).

7 Burkett, S., Ko, N., Stern, N., Caissie, J. \& Sengupta, D. Covalently linked nanocomposites: poly(methyl methacrylate) brushes grafted from zirconium phosphonate. Chem. Mater. 18, 5137-5143 (2006).

8 Shanmugharaj, A., Bae, J., Nayak, R. \& Ryu, S. Preparation of poly(styrene-coacrylonitrile)-grafted multiwalled carbon nanotubes via surface-initiated atom transfer radical polymerization. J. Polym. Sci. Part A: Polym. Chem. 45, 460-470 (2006).

9 Sengonul, M., Ruzicka, J., Attygalle, A. \& Libera, M. Surface modification of protein nanocontainers and their self-directing character in polymer blends. Polymer 48, 3632-3640 (2007).

10 Zhang, J., Yang, Y., Zhao, C. \& Zhao, H. PS/PMMA mixed polymer brushes on the surface of clay layers: preparation and application in polymer blends. J. Polym. Sci. Part A: Polym. Chem. 45, 5329-5338 (2007).

11 Retsos, H., Kiriy, A., Senkovskyy, V., Stamm, M., Feldstein, M. \& Creton, C. Controlling tack with bicomponent polymer brushes. Adv. Mater. 18, 2624-2628 (2006).

12 Makal, U., Uslu, N. \& Wynne, K. Water Makes it hydrophobic: contraphilic wetting for polyurethanes with soft blocks having semifluorinated and 5,5-dimethylhydantoin side chains. Langmuir 23, 209-216 (2007).

13 Mizutani, A., Kikuchi, A., Yamato, M., Kanazawa, H. \& Okano, T. Preparation of thermoresponsive polymer brush surfaces and their interation with cells. Biomaterials 29, 2073-2081 (2008).

14 Schrinner, M., Polzer, F., Mei, Y., Lu, Y., Haupt, B., Ballauff, M., Goldel, A., Drechsler, M., Preussner, J. \& Glatzel, U. Mechanism of the formation of amorphous gold nanoparticles within spherical polyelectrolyte brushes. Macromol. Chem. Phys. 208, 1542-1547 (2007).

15 Luzinov, I., Minko, S. \& Tsukruk, V. V. Responsive brush layers: from tailored gradients to reversibly assembled nanoparticles. Soft Matter 4, 714-725 (2008).

16 Zdyrko, B., Kinnan, M., Chumanov, G. \& Luzinov, I. Fabrication of optically active flexible polymer films with embedded chain-like arrays of silver nanoparticles. Chem. Commun. 1284-1286 (2008).

17 Zhou, L. \& Ma, Y. Phase behavior of nanoparticle-copolymer films confined between polymer-grafted surfaces. J. Phys. - Condensed Matter 20, 095006 (2008).

18 Brittain, W. \& Minko, S. A structural definition of polymer brushes. J. Polym. Sci. Part A: Polym. Chem. 45, 3505-3512 (2007).

19 Kent, M. A quantitative study of tethered chains in various solution conditions using langmuir diblock copolymer monolayers. Macromol. Rapid Commun. 21, 243-270 (2000).
20 Parsonage, E., Tirrell, M., Wanatabe, H. \& Nuzzo, R. Adsorption of poly(2-vinylpyridine) poly(styrene) block copolymers from toluene solutions. Macromolecules 24, 1987-1995 (1991).

21 Cosgrove, T., Heath, T., Ryan, K. \& Crowley, T. Neutron-scattering from adsorbed polymer layers. Macromolecules 20, 2879-2882 (1987).

22 Dyer, D. Photoinitiated synthesis of grafted polymers. Adv. Polym. Sci. 197, 47-65 (2006).

23 Bianconi, P., Joray, S., Aldrich, B., Sumranjit, J., Duffy, D., Long, D., Lazorcik, J., Raboin, L., Kearns, J., Smulligan, S. \& Babyak, J. Diamond and diamond-like carbon from a preceramic polymer. J. Am. Chem. Soc. 126, 3191-3202 (2004).

24 Best, S., Bianconi, P. \& Merz, K. Structural analysis of Carbyne network polymers. J. Am. Chem. Soc. 117, 9251-9258 (1995).

25 Visscher, G. T. \& Bianconi, P. A. Synthesis and characterization of polycarbynes, a new class of carbon-based network polymers. J. Am. Chem. Soc. 116, 1805-1811 (1994).

26 Paquette, L. A., Lagerwall, D. R. \& Korth, H. G. The dodecahedryl radical—reactivity analysis by conjugate addition to pi-electron-deficient acceptors and structural investigation by electron-spin-resonance spectroscopy. J. Org. Chem. 57, 5413-5419 (1992).

27 Jhaveri, S., Beinhoff, M., Hawker, C., Carter, K. \& Sogah, D. Chain-end functionalized nanopatterned functionalized polymer brushes grown via in situ nitroxide free radical exchange. ACS Nano. 2, 719-727 (2008).

28 Tsuji, Y., Ohno, K., Yamamoto, S., Goto, A. \& Fukuda, T. Structure and properties of high-density polymer brushes prepared by surface-initiated living radical polymerization. Adv. Polym. Sci. 197, 1-45 (2006).

29 Zhu, H., Deng, G. \& Chen, Y. Amphiphilic polymer brushes with alternating PCL and PEO grafts through radical copolymerization of styrenic and maleimidic macromonomers. Polymer 49, 405-411 (2008).

30 Juong, M., Ahn, J., Lee, D. \& Yoon, N. Coupling reaction of alkenes with r-bromo carboxylic acid derivatives using nickel boride and borohydride exchange resin in methanol. J. Org. Chem. 63, 2755-2757 (1998).

31 Naji, L., Kaufmann, J., Huster, D., Schiller, J. \& Arnold, K. C-13 NMR relaxation studies on cartilage and cartilage components. Carbohydr. Res. 327, 439-446 (2000).

32 Burrows, H. D., Knaapila, M., Monkman, A. P., Tapia, M. J., Fonseca, S. M., Ramos, M. L., Pyckhout-Hintzen, W., Pradhan, S. \& Scherf, U. Structural studies on cationic poly\{9,9-bis[6-(N,N,N-trimethylammonium) alkyl]fluorene-co-1,4-phenylene\} iodides in aqueous solutions in the presence of the non-ionic surfactant pentaethyleneglycol monododecyl ether. J. Phys.-Condensed Matter 20, 104210 (2008).

33 Digilov, M., Vilcev, K., Zhikharev, A., Kovalev, A., Maluchkov, O., Sternin, S., Ilizarov, L. \& Kostikov, V. Deposition of carbon-based coatings on the surface of carbon-fibers. Carbon 31, 365-371 (1993). 